\title{
Risk Factors for Diverticulosis, Diverticulitis, Diverticular Perforation, and Bleeding: A Plea for More Subtle History Taking
}

\author{
Stephan K. Böhm \\ Medizinische Universitätsklinik, Kantonsspital Baselland, Bruderholz, Switzerland
}

\section{Keywords}

Diverticular disease - Risk factors - Diet - Fiber . Physical activity $\cdot$ Comorbidity $\cdot$ Medication

\section{Summary}

Background: Diverticulosis is a very common condition. Around $20 \%$ of diverticula carriers are believed to suffer from diverticular disease during their lifetime. This makes diverticular disease one of the clinically and economically most significant conditions in gastroenterology. The etiopathogenesis of diverticulosis and diverticular disease is not well understood. Epidemiological studies allowed to define risk factors for the development of diverticulosis and the different disease entities associated with it, in particular diverticulitis, perforation, and diverticular bleeding. Methods: A comprehensive literature search was performed, and the current knowledge about risk factors for diverticulosis and associated conditions reviewed. Results: Non-controllable risk factors like age, sex, and genetics, and controllable risk factors like foods, drinks, and physical activity were identified, as well as comorbidities and drugs which increase or decrease the risk of developing diverticula or of suffering from complications. In naming risk factors, it is of utmost importance to differentiate between diverticulosis and the different disease entities. Conclusion: Risk factors for diverticulosis and diverticular disease may give a clue towards the possible etiopathogenesis of the conditions. More importantly, knowledge of comorbidities and particularly drugs conferring a risk for development of complicated disease is crucial for patient management.

\section{Introduction}

Diverticulosis is one of the most frequent benign conditions of the colon, with a prevalence which is less than $10 \%$ below 40 years of age but amounts to about $30 \%$ up to age 60 and $50-70 \%$ in the over 80 s. Among patients with diverticulosis, about $20 \%$ will develop diverticular disease in their lifetime. Diverticular disease therefore is among the clinically and economically most significant diseases in gastroenterology. In 2004, in the USA, diverticular disease was the third most common gastrointestinal hospital discharge diagnosis and the fourth most common reason for ambulatory care visits. Regarding direct costs attributable to individual digestive diseases, diverticular disease came in fifth place with USD 3.6 billion $[1,2]$. The etiopathogenesis of diverticulosis and diverticular disease is not well understood. Epidemiology, however, teaches us that there are certain factors associated with an increased risk of developing diverticulosis or diverticular disease. Frequently, the discussion about risk factors for these conditions suffers from an imprecise separation of entities. We emphasize therefore that risk factors for diverticulosis, diverticulitis, diverticular perforation, and bleeding from a diverticulum have to be treated separately. As an example, dietary fiber as a risk factor or protective factor in diverticulosis and associated diseases has attracted a lot of attention. Recent studies questioned the long-held hypothesis that a diet rich in fiber protects against the development of diverticula. In the discussion that ensued, the fact that there is very strong evidence that a fiber-rich diet protects against the development of diverticular disease was almost forgotten. There are risk factors which cannot be influenced, such as age, sex, and genetics; however, with regard to eating, drinking, and physical activity, lifestyle choices can be made. More importantly, comorbidities and particularly drugs are also powerful risk factors for the development of diverticulitis, perforation, or bleeding. Careful history taking allows to reduce a patient's risks by e.g. selecting less harmful medication, and may guide therapeutic decisions based on certain comorbidities.

\section{KARGER \\ Fax +497614520714


This review summarizes the current literature regarding the risk factors for diverticulosis and diverticular disease including non-controllable and controllable factors, comorbidities, and medication.

\section{Non-Controllable Risk Factors: Age, Sex, and Genetics}

$$
\text { Age }
$$

Since diverticulosis not necessarily causes symptoms, its prevalence is difficult to estimate. On the basis of colon double contrast enema and autopsy studies that both overestimate the prevalence of diverticulosis, the numbers for Western industrialized nations are approximately $13 \%$ for persons under 50 years of age, $30 \%$ for persons $50-70$ years of age, $50 \%$ for persons $70-85$ years of age, and $66 \%$ for persons older than 85 years [3-6].

The incidence of diverticular disease also demonstrates a clear age dependency, although a slight increase in younger patients was observed during the last decade [7]. In a study from the USA based on a nationwide inpatient registry performed between 1998 and 2005, the number of patients treated for diverticular disease increased by $26 \%$ while the average age dropped from 64.6 to 61.8 years during that time period. The incidence in 1998 was highest for patients aged 75 years and older with 2,447/1 million, and decreased rapidly in the younger age groups with 1,360/1 million for patients aged 65-74 years, 659/1 million for the age group 45-64 years, and 151/1 million for patients aged 18-44 years [8]. The incidence rose strongest in the time interval applying to the age group 18-44 years (to 251/1 million) followed by the group aged $45-64$ years (to 777/1 million); in comparison, the incidence remained stable in the age group 65-74 years and dropped in the group of patients 75 years and older [8]. In a similar analysis covering the period from 2002 to $2007,29.6 \%$ of patients admitted for diverticulitis were 49 years and younger, $40.2 \%$ were aged between 50 and 70 years, and $30.2 \%$ were older than 70 years. Similarly, in that more recent period, admissions dropped in the over 75 s by $4.8 \%$, while they increased by $1.3 \%$ in the group aged 49 years and younger and by $3.5 \%$ in the group aged $50-70$ years [9]. In a recent paper, 2,127 persons with colonoscopically detected diverticulosis were followed over a median of almost 7 years. The cumulative probability to develop diverticulitis over 10.8 years was $4.3 \%$; it was highest for the age group $40-49$ years with $11 \%$, and dropped for each further decade by $24 \%$ [10]. A more aggressive clinical course in younger patients described by some authors [11, 12] was not confirmed in more recent studies [13-15].

\section{$\operatorname{Sex}$}

The data regarding a preference for either sex are inhomogeneous $[4,7]$. While early studies demonstrated a male preponderance for diverticular disease [7], studies from the USA in 1998/1999 found a female share of $60.7 \%$ for diverticular disease-associated hospital admissions, which declined to $57.8 \%$ until $2007[8,9]$.

\section{Genetics}

Some rare syndromes demonstrate a strong predisposition for formation of colonic diverticula. Among those are Marfan syndrome, Ehlers-Danlos syndrome, Williams-Beuren syndrome, Coffin-Lowry syndrome, and polycystic kidney disease (PKD) [7, 16-18]. Affected persons develop colonic diverticula from a young age $[4,19,20]$. These syndromes have in common a defect in extracellular matrix components or connective tissue fibers, which suggests also a role for these structures in the pathogenesis of spontaneous diverticulosis. Case reports have hinted at familial risk factors for the development of diverticulosis and diverticular disease in the general population [6]. A recent study using the Swedish Twin Registry comprising 104,552 twins demonstrated that genetic susceptibility is an important component in diverticular disease of the colon with an odds ratio (OR) of 7.15 for developing the disease if one's monocygotic twin is affected, and an OR of 3.20 for same-gender dizygotic twins. Heritability was estimated at $40 \%$, and non-shared environmental effects at $60 \%$ [17].

\section{Controllable Risk Factors: Food, Drink, and Tobacco}

\section{Dietary Fiber}

Since the papers by Painter and Burkitt in the 1960s and 1970s [21], a lack of dietary fiber is firmly anchored in the literature as the most important lifestyle-associated risk factor for the development of diverticulosis as well as diverticular disease $[18,22]$. Their hypothesis was based on striking geographical and time differences in the prevalence of diverticulosis and diverticular disease. In contrast to Western industrial nations, the authors barely found persons affected by diverticulosis in Africa and Asia where a diet rich in dietary fiber is traditionally consumed. Furthermore, since the onset of industrialization, the prevalence of diverticular disease has strongly risen in Europe and the USA, and it was observed that Afro-American and Japanese immigrants developed diverticular disease after adaptation to Western dietary habits [21]. The dietary fiber hypothesis as a basis for the formation of diverticula receives further support from animal research data in rats and rabbits [23, 24].

However, lately, the possible link between the intake of dietary fiber and the development of diverticulosis or diverticular disease has become an increasingly controversial topic. For this discussion, it is especially important to distinguish between the different disease manifestations as defined in classification systems (e.g. the novel Classification of Diverticulitis/Diverticular Disease (CDD)) [25].

The link between diet and diverticulosis (CDD type 0 ) is scientifically difficult to prove for the long latency of diverticula formation, the lack of symptoms of diverticulosis, and the difficult and complex methodology of monitoring dietary habits. A study found with $12 \%$ a lower prevalence for diverticulosis in 56 long-term vegetarians compared to $33 \%$ in 264 non-vegetarians. The fiber intake in the vegetarians was with $41.5 \mathrm{~g} /$ day double that of the non-vegetarians (21.4 g/day) [26]. However, the fiber intake was identical in 
diverticula-carrying and diverticula-free vegetarians, and diverticula-carrying vegetarians consumed with $33.7 \mathrm{~g} /$ day significantly more dietary fiber than diverticula-free non-vegetarians $(22.1 \mathrm{~g} /$ day) [26]. This study therefore points to additional factors besides dietary fiber intake. Two case-control studies $[27,28]$ and three recently published cross-sectional studies [29-31] found either no effect of dietary fiber intake or an even positive correlation between fiber intake and diverticulosis. In the Korean study [29], however, $85 \%$ had right-sided diverticulosis, which may differ in terms of pathogenesis from left-sided diverticulosis. Furthermore, this study used a quite simple instrument to measure fiber intake, and did not report the time period of dietary habit monitoring [29]. The two well published back-to-back US American colonoscopy-based cross-sectional studies of dietary risk factors for diverticulosis also challenged the dietary fiber hypothesis [30,31]. These studies generated a lot of attention and sparked a welcome discussion [22, 32-36]. However, their significance in challenging the dietary fiber hypothesis should not be overrated due to their cross-sectional study design and the recording of only the most recent fiber intake. Diverticulosis takes decades to develop, and the recording of lifelong dietary and bowel habits would be necessary for more meaningful conclusions. For the time being, there is agreement that there are considerable benefits of fiber for the management of other diseases and overall health; we therefore should continue to recommend fiber as part of a healthy diet $[33,34]$.

Regarding the influence of a fiber-rich diet on mild diverticular disease (mostly CDD type 1 and CDD type 3a), there are some uncontrolled studies [37-39] as well as at least five small randomized controlled studies [40-44]. All but one study [40] found a positive effect of dietary intervention on symptoms or on surrogate parameters like reduced colon transit time, higher stool weight, or normalization of sigma muscle activity. The only negative study was criticized for the low amount of dietary fiber consumed [22, 40, 45]. More recent reviews have emphasized the low quality of available data (evidence level II and III) [46, 47].

Several studies, among them three big prospective cohort studies, have suggested that a diet rich in dietary fiber results in a risk reduction for the development of both acute uncomplicated (CDD type 1) and acute complicated diverticulitis (CDD type 2). In the Health Professionals Follow-Up Study (HPFS) encompassing 48,000 men, individuals with the highest fiber intake ( $>32 \mathrm{~g} /$ day) had a risk reduction of $42 \%$ for development of diverticulitis compared to those with the lowest fiber intake [48]. The protective effect is thought to be mediated by insoluble fiber found in fruit and vegetables [49]. Comparable data have been reported from a cohort encompassing 47,033 men and women from England and Scotland (EPIC) [50]. Individuals with the highest intake of dietary fiber ( $\geq 25.5 \mathrm{~g} /$ day for women and $\geq 26.1 \mathrm{~g} /$ day for men) had a risk reduction of $42 \%$ for hospital admission and inpatient treatment compared to individuals with the lowest intake of dietary fiber $(<14 \mathrm{~g} /$ day for men and women) [50]. In the Million Women cohort encompassing 690,075 middle-aged women, participants with the highest fiber intake ( $>17.6 \mathrm{~g} /$ day) had a relative risk (RR) of 0.75 for admission or death from diverticular disease. The strong- est effect was noted for cereal and fruit fiber [51]. A case-control study [52] as well as a retrospective cohort study [53] have also reported a protective effect of a diet rich in fiber.

\section{Nuts, Grains, Corn, Popcorn}

Because of the notion that undigested particles of nuts, grains, corn, or popcorn remain lodged in portions of the diverticulum and can lead to an accumulation of complications, people with diverticula and other patients have long been advised to avoid these foods. However, an analysis of the HPFS cohort indicated that consumption of nuts and grains does not elevate the risk of diverticulitis or diverticular hemorrhage. In contrast, consumption of nuts or popcorn at least $2 \times /$ week was found to reduce the risk by $20 \%$ for nuts and $27 \%$ for popcorn [54].

\section{Red Meat}

A recently published cross-sectional colonoscopy-supported study of 2,104 subjects found no relationship between the consumption of red meat and the prevalence of diverticulosis [30]. However, a Taiwanese case-control study examined 86 patients with right-sided diverticulosis and 106 matched controls; this study found that individuals who consumed red meat at least once per day had 25 times the risk of developing diverticulosis compared to those who ate red meat less than once a week [28].

A case-control study and two large-scale prospective cohort studies revealed that frequent consumption of red meat is a risk factor for diverticular disease or for hospitalization as a result of diverticular disease [48, 49, 52]. The study by Manousos et al. [52] showed that among individuals who ate beef or lamb at least twice a week, the risk of hospitalization was 1.89 times or 3.86 times higher, respectively, compared to individuals who ate these meats only once per week. In the HPFS cohort, frequent consumption of red meat led to an increased risk of diverticular disease, although there was no dose effect. Similarly, consumption of 39.4, 65.9, 97.4, or $144.4 \mathrm{~g}$ of red meat/day compared to consumption of $16.0 \mathrm{~g} /$ day resulted in a 1.5 times higher risk [48]. When the frequency of consumption of red meat (beef, pork, lamb) as the principle meal was analyzed, the risk was 3.23 times greater for people who ate at least one meat meal per day compared to people who have a meat meal less than once per month [48]. Likewise, in the EPIC cohort, individuals who eat meat had a higher risk of hospitalization due to diverticular disease compared to vegetarians [50].

\section{Other Food Ingredients/Combinations}

A South Korean study found that a diet high in fats was associated with a 1.7 times higher risk of diverticulosis [28]. The work of Peery et al. [30] found no difference in fat consumption between people with diverticula and those without (70.2 vs. $69.2 \mathrm{~g} /$ day). 
There are no data on symptomatic uncomplicated diverticular disease.

Aldoori et al. [48], in the HPFS cohort, found no elevated risk for the development of diverticular disease associated with fat consumption. However, the combination of higher fat intake ( $>81 \mathrm{~g} /$ day) and low fiber ( $<17 \mathrm{~g}$ /day) led to a risk that was 2.35 times greater than with a diet lower in fat $(<47 \mathrm{~g} /$ day $)$ and higher in fiber ( $>29 \mathrm{~g} /$ day). The combination of low-fiber diet and significant consumption of red meat ( $>116.6 \mathrm{~g} /$ day) increased the risk for diverticular disease to 3.22 times that of diets with high fiber ( $29 \mathrm{~g} /$ day) and little red meat $(<28.5 \mathrm{~g} /$ day $)$. A multivariate analysis indicated no association between potassium, $\beta$-carotene, vitamin $\mathrm{C}$ and magnesium, and diverticular disease [48].

\section{Smoking}

One cross-sectional study found that the probability of diverticulosis was 30\% greater among smokers, although this effect was not statistically significant [29]. However, several case-control studies and a large-scale prospective cohort study found an increased risk of diverticular disease. A Swedish cohort consisting of 37,000 women found the risk of hospitalization due to diverticular disease to be $24 \%$ higher among women who smoke [55]. Cessation of smoking only showed an effect after more than 10 years, and was then most pronounced for perforation [55]. In a cohort of 7,500 Swedish men, there was a $60 \%$ higher risk of hospitalization due to diverticular disease among smokers [56], and in the EPIC cohort a dose effect was seen with a 34 or $86 \%$ increased risk for hospitalization when $<15$ or $>15$ cigarettes were smoked per day, respectively [50]. In the HPFS cohort, which not only considers hospitalized patients, smoking had no significant effect on the risk of diverticular disease [57]. A variety of other studies have suggested a relationship between smoking and severe complicated forms of diverticular disease such as perforation [58-61]. In contrast, three small case-control studies found no relationship between smoking and cumulative diverticular hemorrhage [62-64].

\section{Alcohol}

The South Korean cross-sectional study by Song et al. [29] noted that individuals who consumed alcohol have a risk of diverticulosis that is 2.2 times greater than the risk of people who do not. However, the study does not present data on the type, quantity, and duration of alcohol consumption. The large-scale prospective HPFS cohort study found a higher risk (36\%) of diverticular disease among men who consumed $>30 \mathrm{~g}$ alcohol/day compared to men who abstained from alcohol, but the difference was not significant [57]. However, the difference was significant when the type of alcohol was considered. There was no relationship between diverticular disease and beer or wine, but consumption of spirits or liqueurs revealed a relationship in which consumption of 1-3 measures/month led to a $50 \%$ increase in risk and 2-3 drinks/ day led to a $65 \%$ increase, which does not suggest dose dependency. In the EPIC cohort, an effect of alcohol consumption on hospitalization due to diverticular disease was no longer significant after correction for smoking habits [50]. A Danish study found that patients who were admitted to hospital for alcoholism were also 2.9 times more likely to be hospitalized for diverticulitis than the general population. This work suggests that severe alcohol abuse may have an effect, but did not correct for other confounding factors [65]. Another study of 80 patients recorded similar levels of alcohol consumption in patients with mild to severe forms of diverticular disease [60]. Small-scale case-control studies have documented no relationship between alcohol consumption and frequent diverticular hemorrhage [62-64].

\section{Coffee}

In the HPFS cohort, no relationship between consumption of coffee and diverticular disease has been observed [57].

\section{Controllable Risk Factors: Body Weight, Physical Activity, and Insolation}

\section{Body Weight}

A cross-sectional study [29] and a prospective cohort study [66] found no relationship between body mass index (BMI) and asymptomatic diverticulosis [22]. In contrast, an Israeli colonoscopybased retrospective case-control study involving 3,175 people found that obesity with a BMI $>30$ was associated with a 1.4 times higher risk of diverticulosis [67].

Smaller case series and case-control studies have documented a relationship between being overweight, particularly for younger people, and a frequent occurrence of diverticulitis [11, 68-70]. Three large-scale prospective cohort studies confirm this association: The Swedish study involving 7,500 males found a risk of complicated diverticular disease in men with a BMI $>30$ that was 4 times higher than that of men with a BMI of 20-22.5 [56]. An American study followed 47,000 men over the age of 18, and found that the risk of diverticulitis was $78 \%$ higher for men with a BMI $>30$ compared to men with a BMI $<21$, and the risk of diverticular hemorrhage was 3 times higher [71]. Moreover, after correcting for $\mathrm{BMI}$, the waist-to-hip ratio remained an independent risk factor for complications; this has led to speculation that central adiposity is particularly relevant for the occurrence of diverticular disease due to the release of pro-inflammatory cytokines from the visceral fat $[22,72]$. The third study followed 36,592 Swedish women over a period of 12 years. Women with a BMI between 25 and 29.99 had a $29 \%$ higher risk and women with a BMI $\geq 30$ a $33 \%$ higher risk of diverticular disease compared to women with a BMI of 20-24.99. The risk of abscess or perforation was 2 times higher in women with a $\mathrm{BMI} \geq 30[72]$. 


\section{Physical Activity}

A recently published cross-sectional study of 2,104 participants who evaluated their diet and physical activity using a questionnaire found no relationship between diverticulosis and physical activity [30]. Nevertheless, men who sit for at least $52 \mathrm{~h} /$ week had a $30 \%$ higher risk of diverticulosis than men who sit for less than $16 \mathrm{~h} /$ week [71]. In contrast, several large-scale prospective cohort studies have indicated a reduced risk of complicated diverticular disease, including diverticular hemorrhage, as a result of physical activity, although several studies document this effect only for high activity levels and not for mild exertion such as walking [71-74]. In one study, the effect of intense physical activity led to a $25 \%$ reduction in the risk of diverticulitis and a $46 \%$ reduction in the risk of diverticular hemorrhage compared to men who exercised less intensely [71]. The Swedish study found a $42 \%$ higher risk of diverticular disease in women who trained $\leq 30 \mathrm{~min} /$ day compared to women who exercised $>30 \mathrm{~min} /$ day [72]. Another study found no effect of physical activity on hospitalizations due to diverticular disease [56].

\section{Insolation}

Recent studies in the USA have observed geographical and seasonal variation in hospitalizations for diverticulitis $[75,76]$. Based on that observation, the risk for diverticulitis has been putatively linked to exposure to ultraviolet (UV) radiation and vitamin D serum levels. Observational retrospective studies demonstrated a lower rate of diverticulitis in the winter, a statistically significant higher rate of admissions for diverticulitis in low-UV areas compared to high-UV areas (751.8 vs. 668.1 per 100,000 admissions), and an inverse relationship between 25 -hydroxyvitamin $\mathrm{D}$ serum levels and risk of hospitalization for diverticulitis. Compared to patients in the lowest quintile of vitamin D serum levels, patients in the highest quintile had a multivariate-adjusted RR for diverticulitis-related hospitalization of $0.49[77,78]$.

\section{Risk Factor Comorbidity}

\section{Comorbidity and Diverticulosis}

\section{Hypothyroidism}

An Israeli retrospective case-control study involving 3,175 patients described a risk of diverticulosis that was 2.4 times higher if there was a diagnosis of hypothyroidism in the case history [67].

\section{Diabetes Mellitus}

The same Israeli study found that a diagnosis of diabetes mellitus is a protective factor for the presence of diverticulosis with an OR of 0.49 [67]. In contrast, in a Japanese cross-sectional study involving 954 patients, the prevalence of diabetes mellitus type II in people with a diverticulum (more right-sided) was significantly higher than in people with no diverticulum (21.6 vs. 14.0\%) [79].

\section{Arterial Hypertension}

The Japanese study found that the prevalence of arterial hypertension among people with a diverticulum was significantly higher than in people with no diverticulum (30.9 vs. 19.8\%) [79]. In contrast, the Israeli study found no relationship between arterial hypertension and diverticulosis [67].

\section{Polycystic Kidney Disease}

Of six case series involving a total of 186 patients with PKD [80-85], three made statements about the prevalence of diverticulosis. Scheff et al. [80] documented a prevalence of 10/12 (83\%), Dominguez Fernandez et al. [82] of 15/28 (53.5\%), and Sharp et al. [83] of 28/59 (47\%). In a group of patients with kidney failure but no PKD, Scheff et al. [80] documented a diverticular prevalence of $10 / 31(32 \%)$. In an age-matched comparative group without kidney disease they found a similar diverticular prevalence of 45/120 (38\%). Sharp et al. [83] reported a diverticular prevalence of 35/59 (59\%) in their control group with no PKD and no kidney failure, and concluded that patients with PKD have no higher risk of diverticulosis or diverticular disease than the general population.

\section{Comorbidity and Acute Uncomplicated and Complicated Diverticular Disease}

\section{Arterial Hypertension}

A Swedish prospective cohort study involving 7,500 men reported that a univariate analysis revealed a risk of complicated diverticular disease that was 1.8 times higher in men with a systolic blood pressure of 146-162 mm Hg or $>162 \mathrm{~mm} \mathrm{Hg}$ compared to men with a systolic blood pressure of $<133 \mathrm{~mm} \mathrm{Hg}$. The univariate analysis also demonstrated a risk that was 2.2 times higher in patients with a diastolic blood pressure of $>102 \mathrm{~mm} \mathrm{Hg}$ compared to patients with a diastolic blood pressure of $<88 \mathrm{~mm} \mathrm{Hg}$. Only diastolic blood pressure remained a significant risk factor in multivariate analysis, with a hazard ratio (HR) of 1.02 for each $\mathrm{mm} \mathrm{Hg} \mathrm{[56].}$ This study also considered hemorrhages but did not account for these separately.

\section{Kidney Disease}

A retrospective study from the UK included 202 patients with perforated diverticular disease. Mortality was $24.3 \%$. One risk factor for death was pre-existing kidney disease with an OR of 18.7 [86]. Of six case series including a total of 186 patients [80-85], four made statements about the incidence of diverticular disease. Scheff et al. [80], Lederman et al. [84], and Pourfarziani et al. [85] reported high incidence of severe cases in particular, at 4/12 (33\%), $12 / 59$ (20\%), and 3/18 (17\%), respectively. Only Lederman et al. [84] quantified incidence of diverticular disease in a comparative group with kidney failure but no PKD at 4/125 (3\%). Dominguez Fernandez et al. [82] found no increased risk of diverticular disease $(1 / 28$ or $4 \%)$ even in patients with PKD. No special management of the disease is recommended for patients with PKD compared to the normal patient population [87]. 


\section{Immunosuppression}

A number of different studies hint towards a more severe course of diverticular disease in patients who are immunosuppressed [85-91].

Hwang et al. [92] reviewed the literature, and identified 25 studies of diverticulitis among immunosuppressed patients. All were retrospective cohort studies. 21 studies involved patients who had undergone an organ transplant, of which 13 where kidney transplants and the remaining involved heart, lung, or combined heart and lung transplants. Four studies involved patients undergoing chronic corticosteroid therapy. Overall, 12,729 patients were included in these studies [92]. The incidence of acute diverticulitis among these immunosuppressed patients was $1 \%$ with variable follow-up between 1 month and 17.3 years, and is therefore higher than in the general population. A direct comparison of the incidences in immunosuppressed people and the general population was provided by only one study (0.94 vs. $0.02 \%)$ [93]. When only patients who had known diverticulosis prior to beginning immunosuppression are considered, the incidence of diverticulitis was $15.1 \%$ with variable follow-up [92]. Mortality for all patients with diverticulitis who were treated either conservatively or surgically was $25 \%$, while this number for surgically treated patients was $23 \%$ and hence significantly higher than for the general population, which is reported at $1-5 \%[8,94]$.

There are few data on immunosuppressed patients who did not undergo transplant [92]; hence, no statement can be made about the effects of various immunosuppressive regimens. Similarly, there are no studies involving patients undergoing chemotherapy or patients with human immunodeficiency virus (HIV)/acquired immunodeficiency syndrome (AIDS) [92]. Sachar [95] summarized 15 studies on emergency abdominal surgery in HIV-positive patients. He documented that diverticular disease among HIV/ AIDS patients did not occur more frequently and does not differ in severity from the general population, as long as the CD4 cell count does not drop below $50-200 / \mu 1$ or the viral load does not exceed 10,000-30,000 copies/ml [95].

As a consequence of the higher incidence and mortality of diverticular disease among immunosuppressed patients, screening for diverticulosis prior to beginning immunosuppression has been discussed [92]. However, McCune et al. [81] reported that colonoscopy screening of patients over the age of 50 to detect colon complications post-transplant is not effective. Screening or even prophylactic sigmoid or colon resection are not recommended [87, 92].

\section{Allergic Predisposition}

One research group performed surgery on 101 consecutive patients for either complicated (occult perforation, free perforation, phlegmonous diverticulitis; $\mathrm{n}=57$ ) or non-complicated (chronic recurrent diverticulitis, elective due to comorbidities; $n=44$ ) diverticular disease. This group reported that $39 \%$ of patients had a history of an allergic predisposition to grasses, pollen, food items, medications, pets, or other substances. Patients with an allergic predisposition had an OR of 3.2 for surgery due to a complicated diverticulitis [96].

\section{Comorbidity and Diverticular Hemorrhage}

\section{Arterial Hypertension}

Four studies addressed the role of arterial hypertension in diverticular hemorrhage. Yamada et al. [64] carried out a case-control study and found that 44 of 1,753 patients with diverticulosis had diverticular hemorrhage. The OR for diverticular hemorrhage among patients with arterial hypertension was 6.6. In another case-control study from Japan, 45 of 254 patients with diverticulosis had diverticular hemorrhage. The OR for diverticular hemorrhage among patients with arterial hypertension was 2.2 [97]. A third Japanese case-control study analyzed 51 lower gastrointestinal hemorrhages caused by diverticula, and found a significant risk for patients $<65$ years of age with arterial hypertension [62]. Jansen et al. [63] identified 30 patients with diverticular hemorrhage out of 140 with diverticular disease in a retrospective case series. In this analysis, arterial hypertension was not an independent risk factor for hemorrhage, although medication including calcium antagonists used to treat arterial hypertension may have been a factor.

\section{Hyperlipidemia}

The Japanese case-control study by Tsuruoka et al. [62] reported an OR of 2.2 for diverticular hemorrhage in patients with hyperlipidemia.

\section{Coronary Heart Disease}

The Japanese case-control studies by Tsuruoka et al. [62] and Niikura et al. [97] reported an OR of 1.9 and 2.4, respectively, for diverticular hemorrhage in patients with coronary heart disease.

\section{Chronic Kidney Failure}

The Japanese case-control study by Niikura et al. [97] reported an OR of 6.4 for diverticular hemorrhage in patients with chronic kidney failure.

\section{Hyperuricemia}

Jansen et al. [63] documented an increased risk of diverticular hemorrhage in patients with uricemia. 6 (20\%) of 30 patients with diverticular hemorrhage suffered from hyperuricemia or were taking allopurinol. Of the 110 patients who did not suffer from hemorrhage, either hyperuricemia or uric acid-lowering drug usage were documented in only 8 (7.3\%) patients.

\section{Comorbidity and Indication for Elective Prophylactic Resection}

The following comorbidities and conditions, the majority of which showed a relationship with elevated morbidity or mortality in elective or emergency procedures for diverticular disease in case series, have been described: diabetes mellitus $[98,99]$, cardiac insufficiency [100], chronic obstructive pulmonary disease [100, 101], renal insufficiency [102], autoimmune disorders/vasculitis $[99,102]$, gouty arthritis [98], immunosuppression [99, 102], hy- 
poalbuminemia [101], use of steroids [99, 101], and American Society of Anesthesiologists (ASA) category III/IV [103]. Some authors therefore recommend that a prophylactic sigmoid resection is considered for these risk groups [98, 99, 102]. However, a study by Chapman et al. [99] found that $89.5 \%$ of patients who died of diverticular perforation did not have a history of diverticulosis or diverticular disease, so prophylactic intervention should not be performed on this group. Sheer et al. [100] concluded that the high morbidity and mortality of the risk groups can outweigh the potential benefit of elective surgery. There are insufficient data to define risk groups that should in general receive a prophylactic elective resection of the portion of the colon containing the diverticulum [99].

\section{Colon Cancer and Diverticular Disease}

The hypothesis that patients with diverticular disease have a higher risk of colon cancer was proposed in the 1970s by Burkitt $[104,105]$, and was supported by a study in which $20 / 65$ (31\%) patients with diverticular disease had a neoplastic lesion [106] as well as a case-control study in which 36/150 (24\%) patients with diverticular disease had a neoplastic lesion and therefore a 3 times greater risk than the control group [107]. A retrospective Swedish cohort study reported that people with diverticulosis had a risk of developing colon cancer that was 1.8 times higher than people who did not [108]. A series of new studies involving a large collective no longer found a relationship between diverticulosis or diverticular disease and an elevated risk of adenoma or colorectal cancer [109111]. The authors of this study explain the discrepancy in the data as the result of overdiagnosis of neoplastic lesions associated with an attack of diverticular disease [111, 112]. Based on a 31 times higher risk of a colon cancer diagnosis especially in the first 6 months after a diverticulitis attack, they recommend no special screening interval for people with diverticulosis; instead, a onetime screening after the first attack of diverticulitis is suggested [18, $105,111,112]$.

\section{Risk Factor Medication}

\section{Medications and Acute Uncomplicated and Complicated Diverticular Disease}

\section{NSAIDs and Aspirin}

Reports of the negative effects of non-steroidal anti-inflammatory drugs (NSAIDs) on the course of diverticular disease have been around for almost 30 years. Case study collections and casecontrol studies report an up to 4.85 times higher risk of severe symptomatic diverticular disease in individuals taking NSAIDs [113-115], and a 1.8-3.56 times higher risk of perforation [116120]. Morris et al. [121] reported a risk of death due to perforated diverticulitis that was 3.1 times higher in people taking NSAIDs. The large-scale HPFS cohort was prospectively studied twice for the effects of aspirin and NSAIDs on complications due to diverticular disease. In the 1998 study by Aldoori et al. [122], regular use of NSAIDs, but not aspirin, led to symptomatic diverticular disease with an RR of 2.2. The second analysis involved significantly more data. In that analysis, there was now a risk of developing diverticulitis that was 1.72 or 1.25 times higher among patients who regularly took NSAIDs or aspirin compared to those who took neither of these drugs [123]. NSAIDs were more strongly associated with complicated diverticulitis (HR 2.55) than with uncomplicated diverticulitis (HR 1.65). There was no difference in this regard with aspirin [123].

In the analysis of the risk associated with aspirin, the lack of data on dose and frequency of use in most studies poses a particular problem. Strate et al. [123] attempted to standardize the data and found no strictly linear dependency on the quantity taken. Hence, people who took 2-5.9 aspirin tablets (325 mg) per week had a greater risk of diverticulitis with an HR of 1.26 compared to people who took $\geq 6$ tablets (HR 1.11). On the other hand, daily use of aspirin of unknown dose carried a greater risk of diverticulitis (HR 1.46) than use 4-6 times per week (HR 1.24) [123]. In casecontrol studies by Piekarek et al. [120] and Humes et al. [124], involving 54 and 899 patients, respectively, with diverticular perforations, the use of aspirin was not associated with increased risk. In Humes' study [124], current use of NSAIDs was not associated with a significantly higher risk (OR 1.51), although a history of NSAID use was associated with a significantly greater risk of perforation (OR 1.62).

\section{Acetaminophen}

The first analysis of the HPFS cohort in 1998 found that people who regularly took acetaminophen had a risk of symptomatic diverticular disease that was 1.81 times higher [120].

\section{Coxibs}

In their population-based case-control study involving 899 patients with diverticular perforation and 8,980 controls, Humes et al. [124] found use of coxibs to be infrequent. $7.8 \%$ of the cases and $3.0 \%$ of the controls had taken these substances at some point. For comparison, $66 \%$ of the cases and $52 \%$ of the controls reported having taken NSAIDs at some point. After correcting for confounding variables, current use of a coxib was no longer associated with an increased risk of perforation.

\section{Corticosteroids}

Case collections and small-scale hospital-based case-control studies since the 1970s have reported a risk of primarily diverticular perforations that was 13-32 times greater among people taking corticosteroids $[113,119-121,125,126]$. The population-based case-control study by Humes et al. [124] reported a risk of diverticular perforation that was 2.74 times greater among people currently taking corticosteroids and 1.69 times greater among people who took steroids at some point in their medical history. There is a particularly high risk among patients with a lack of severe comorbidities (OR 6.45). 


\section{Opioids}

The hospital-based case control studies by Morris et al. [121] and Piekarek et al. [120] reported a risk of diverticular perforation that was 1.8-4.5 times higher among people taking opioids. The population-based case-control study of Humes et al. [124] found a risk of diverticular perforation that was 2.16 times greater among people currently taking opioid analgesics, and 1.88 times greater among people who took opoids at some point in their medical history.

\section{Calcium Antagonists}

The hospital-based case-control studies by Morris et al. [127] and Piekarek et al. [120] reported a protective effect of calcium antagonists against diverticular perforation with an OR between 0.14 and 0.41. Likewise, the population-based case-control study of Humes et al. [124] documented a potential protective role against diverticular perforation.

\section{Statins}

The population-based case-control study by Humes et al. [124] found a risk reduction (OR 0.44) for diverticular perforation among people currently taking statins, but no effect was seen if statins had been used earlier in the medical history.

\section{Medication and Diverticular Hemorrhage}

\section{NSAIDs and Aspirin}

Since the report by Langman et al. [116] about the potential role of NSAIDs as a risk factor for diverticular hemorrhage, two Japanese case-control studies have reported a risk of diverticular bleeding that was 7.5-15.6 times higher $[62,64]$. The first analysis of the HPFS cohort by Aldoori et al. [122] found a risk that was 4.64 times higher for people taking NSAIDs [122]. In the update to the prospective cohort study by Strate et al. [123], the risk of diverticular hemorrhage for regular use of NSAIDs alone was 1.74 times higher, for aspirin alone 1.70 times higher, and for the combination of NSAIDs and aspirin 2.02 times higher [123]. Surprisingly, for aspirin, there appears to be no linear dose-effect relationship, with the highest risk among people taking 2-5.9 tablets (325 mg) per week (HR 2.32), while taking $0.1-1.9$ or $\geq 6$ tablets had a lower risk of a similar magnitude, with an HR of 1.58 or 1.65 , respectively. In terms of the frequency of aspirin use, people who used the drug 4-6 times per week (HR 3.13) had a significantly higher risk of hemorrhage compared to people who used the drug daily (HR 1.57) or 2-3.9 times per week (HR 1.21) [123].

\section{Acetaminophen}

In the first analysis of the HPFS cohort, Aldoori et al. [122] reported a 13.63 times increased risk of diverticular hemorrhage in patients using acetaminophen.

\section{Aspirin (Low-Dose) and Other Anticoagulants}

Only one study has investigated the risk of diverticular hemorrhage among people taking the currently most common dose of
$100 \mathrm{mg}$ of aspirin. In their hospital-based case-control study, Yamada et al. [64] reported an OR of 3.7 from a univariate analysis. Other thrombocyte aggregation inhibitors such as cilostazol, sarpogelate, and dipyridamole had an OR of 2.3 in univariate analyses. ASA100 and other thrombocyte aggregation inhibitors were pooled in the multivariate analysis, and the result was an OR of 3.0 [64]. A Spanish population-based study identified 2,130 diverticular hemorrhages. Concomitant medication was examined in 189 cases. The study indicated that 'low-dose' aspirin was the most common concomitant medication at $21.7 \%$, while NSAIDs and anticoagulants were approximately the same at 14.8 and $14.3 \%$, respectively [128].

\section{Corticosteroids}

In the hospital-based case-control study by Jansen et al. [63] of 140 patients with diverticular disease, 30 were identified as having diverticular hemorrhage. 4/30 (13.3\%) patients with diverticular hemorrhage were taking steroids compared to $4 / 110$ (2.7\%) in the group of patients with no diverticular hemorrhage. A multivariate analysis revealed that taking steroids is an independent risk factor for diverticular hemorrhage.

\section{Calcium Antagonists}

In the study by Jansen et al. [63], 10/30 (33.3\%) patients with diverticular hemorrhage were taking calcium antagonists compared to $23 / 110$ (20.9\%) in the group of patients with no diverticular hemorrhage. A multivariate analysis revealed that taking calcium antagonists is an independent risk factor for diverticular hemorrhage.

\section{Conclusion}

In summary, the epidemiological studies reviewed here teach us:

- that the risk for development of diverticulosis and diverticular disease is age-dependent and that both genetic and environmental factors play an important role;

- that there are very robust data that dietary fiber has a strong protective effect against development of diverticular disease; a diet rich in fiber therefore should be recommended to all those carrying colonic diverticula; while the data supporting the fiber hypothesis (a lack of dietary fiber is a risk factor for the development of diverticula) may be less solid, there is general agreement that there are considerable benefits of fiber for the management of other diseases and overall health so that we should continue to recommend fiber as part of a healthy diet; while nuts, grains, corn, and popcorn are shown in big cohort studies to be protective against the development of diverticular disease, red meat and smoking are risk factors;

- that being overweight is a risk factor for developing diverticular disease while physical activity is protective;

- that there is solid evidence that arterial hypertension and immunosuppression are conditions enhancing the risk of developing diverticular disease; 
- that NSAIDs, aspirin, acetaminophen, corticosteroids, and opioids enhance the risk for both development of diverticular disease and diverticular hemorrhage;

- that therefore the history of persons with diverticula should include an array of lifestyle factors, comorbidities, and current medication;

- and finally that the information gained should result in comprehensive recommendations; for example protective lifestyle factors should be encouraged, comorbidities like arterial hyper- tension treated, and medication that increases the risk for diverticulosis complications avoided whenever possible; careful history taking is therefore of utmost importance for the management of persons with diverticula.

\section{Disclosure Statement}

No conflict of interest.

\section{References}

1 Everhart JE, Ruhl CE: Burden of digestive diseases in the United States part I: overall and upper gastrointestinal diseases. Gastroenterology 2009;136:376-386.

2 Everhart JE, Ruhl CE: Burden of digestive diseases in the United States part II: lower gastrointestinal diseases. Gastroenterology 2009;136:741-754.

3 Humes DJ: Changing epidemiology: does it increase our understanding? Dig Dis 2012;30:6-11.

4 Jun S, Stollman N: Epidemiology of diverticular disease. Best Pract Res Clin Gastroenterol 2002;16:529-542.

5 Delvaux M: Diverticular disease of the colon in Europe: epidemiology, impact on citizen health and prevention. Aliment Pharmacol Ther 2003;18(suppl 3): 71-74.

6 Commane DM, Arasaradnam RP, Mills S, et al: Diet, aging and genetic factors in the pathogenesis of diverticular disease. World J Gastroenterol 2009;15:2479_ 2488.

7 Weizman AV, Nguyen GC: Diverticular disease: epidemiology and management. Can J Gastroenterol 2011; 25:385-389.

8 Etzioni DA, Mack TM, Beart RW Jr, et al: Diverticulitis in the United States: 1998-2005. Changing patterns of disease and treatment. Ann Surg 2009;249:210-217.

$\checkmark 9$ Masoomi H, Buchberg BS, Magno C, et al: Trends in diverticulitis management in the United States from 2002 to 2007. Arch Surg 2011;146:400-406

10 Strate LL, Modi R, Cohen E, et al: Diverticular disease as a chronic illness: evolving epidemiologic and clinical insights. Am J Gastroenterol 2012;107:1486-1493.

$\checkmark 11$ Schauer PR, Ramos P, Ghiatas AA, et al: Virulent diverticular disease in young obese men. Am J Surg 1992; 164:443-446.

12 Minardi AJ Jr, Lohnson LW, Sehon JK, et al: Diverticulitis in the young patient. Am Surg 2001;67:458-461.

13 Hjern F, Josephson T, Altman D, et al: Outcome of younger patients with acute diverticulitis. $\mathrm{Br}$ J Surg 2008;758-764

14 Janes S, Meagher A, Faragher IG, et al: The place of elective surgery following acute diverticulitis in young patients: when is surgery indicated? An analysis of the literature. Dis Colon Rectum 2009;52:1008-1016.

15 Faria GR, Almeida AB, Moreira H, et al: Acute diverticulitis in younger patients: any rationale for a different approach? World J Gastroenterol 2011;17:207-212.

16 Petruzziello L, Iacopini F, Buljic M, et al: Review article: uncomplicated diverticular disease of the colon. Aliment Pharmacol Ther 2006;23:1379-1391.

17 Granlund J, Svensson T, Olen O, et al: The genetic influence on diverticular disease - a twin study. Aliment Pharmacol Ther 2012;35:1103-1107.

18 Böhm S: Epidemiologie, natürlicher Verlauf, Prognose; in Kruis W, Leifeld L (eds): Divertikelkrankheit. Bremen, Uni-Med, 2010.
Afzal NA, Thomson M: Diverticular disease in adolescence. Best Pract Res Clin Gastroenterol 2002;16:621634.

20 Santin BJ, Prasad V, Caniano DA: Colonic diverticulitis in adolescents: an index case and associated syndromes. Pediatr Surg Int 2009;25:901-905.

21 Painter NS, Burkitt DP: Diverticular disease of the colon: a deficiency disease of western civilization. $\mathrm{Br}$ Med J 1971;ii:450-454.

22 Strate LL: Lifestyle factors and the course of diverticular disease. Dig Dis 2012;30:35-45.

23 Carlson AJ, Hoelzel F: Relation of diet to diverticulosis of the colon in rats. Gastroenterology 1949;12:108-115.

24 Fisher N, Berry CS, Fearn T, et al: Cereal dietary fiber consumption and diverticular disease: a lifespan study in rats. Am J Clin Nutr 1985;42:788-804.

25 Leifeld L, Germer CT, Böhm S, et al: S2k guidelines diverticular disease/diverticulitis (Article in German). Z Gastroenterol 2014;52:663-710.

26 Gear JS, Ware A, Fursdon P, et al: Symptomless diverticular disease and intake of dietary fibre. Lancet 1979;i:511-514.

27 Manousos ON, Vrachliotis G, Papaevangelou G, et al: Relation of diverticulosis of the colon to environmental factors in Greece. Am J Dig Dis 1973;18:174-176.

28 Lin OS, Soon MS, Wu SS, et al: Dietary habits and right-sided colonic diverticulosis. Dis Colon Rectum 2000;43:1412-1418.

29 Song JH, Kim YS, Lee JH, et al: Clinical characteristics of colonic diverticulosis in Korea: a prospective study. Korean J Intern Med 2010;25:140-146.

30 Peery AF, Barrett PR, Park D, et al: A high-fiber diet does not protect against asymptomatic diverticulosis. Gastroenterology 2012;142:266-272.

31 Peery AF, Sandler RS, Ahnen DJ, et al: Constipation and low-fiber diet are not associated with diverticulosis. Clin Gastroenterol Hepatol 2013;11:1622-1627.

32 Peery AF, Sandler RS: Diverticular disease: reconsidering conventional wisdom. Clin Gastroenterol Hepatol 2013;11:1532-1527.

33 Burgell RE, Muir JG, Gibson PR: Pathogenesis of colonic diverticulosis: repainting the picture. Clin Gastroenterol Hepatol 2013;11:1628-1630.

34 Floch MH: Is there really anything new on dietary fiber in colonic diverticular disease? Clin Gastroenterol Hepatol 2014;12:1200-1201.

35 Meyer GW: Diverticulosis is a disease of civilization. Clin Gastroenterol Hepatol 2014;12:1580

36 Strate LL: Diverticulosis and dietary fiber: rethinking the relationship. Gastroenterology 2012;142:205-207.

37 Brodribb AJ, Humphreys DM: Diverticular disease: three studies. III. Metabolic effect of bran in patients with diverticular disease. Br Med J 1976;i:428-430.

38 Painter NS, Almeida AZ, Colebourne KW: Unprocessed bran in treatment of diverticular disease of the colon. Br Med J 1972;ii:137-140.
9 Hyland JM, Taylor I: Does a high fibre diet prevent the complications of diverticular disease? Br J Surg 1980; 67:77-79.

40 Ornstein MH, Littlewood ER, Baird IM, et al: Are fibre supplements really necessary in diverticular disease of the colon? Br Med J (Clin Res Ed) 1981;282:1629-1630.

41 Taylor I, Duthie HL: Bran tablets and diverticular disease. Br Med J 1976;i:988-990.

42 Hodgson WJ: The placebo effect. It is important in diverticular disease? Am J Gastroenterol 1977;67:157162.

43 Brodribb AJ: Treatment of symptomatic diverticular disease with a high-fibre diet. Lancet 1977;i:664-666.

44 Smits BJ, Whitehead AM, Prescott P: Lactulose in the treatment of symptomatic diverticular disease: a comparative study with high-fibre diet. Br J Clin Pract 1990;44:314-318.

45 Thornton JR: Are fibre supplements really necessary in diverticular disease of the colon? Br J Med (Clin Res Ed) $1981 ; 282: 1546-1547$.

46 Smith J, Humes DJ, Spiller R: Should we treat uncomplicated symptomatic diverticular disease with fibre? BMJ 2011;342:d2951.

47 Ünlü C, Daniles L, Vrouenraets BC, et al: A systematic review of high-fibre dietary therapy in diverticular disease. Int J Colorectal 2012;27:419-427.

48 Aldoori WH, Giovanucci EL, Rimm EB, et al: A prospective study of diet and the risk of symptomatic diverticular disease in men. Am J Clin Nutr 1994;60: 757-764.

49 Aldoori WH, Giovanucci EL, Rockett HR, et al: A prospective study of dietary fiber types and symptomatic diverticular disease in men. J Nutr 1998;128:714-719.

50 Crowe FL, Appleby PN, Allen NE, et al: Diet and risk of diverticular disease in Oxford cohort of European Prospective Investigation into Cancer and Nutrition (EPIC): prospective study of British vegetarians and non-vegetarians. BMJ 2011;343.

51 Crowe FL, Balkwill A, Cairns BJ, et al: Source of dietary fibre and diverticular disease incidence: a prospective study of UK women. Gut 2014;63:1450-1456.

52 Manousos O, Day NE, Tzounou A, et al: Diet and other factors in the aetiology of diverticulosis: an epidemiological study in Greece. Gut 1985;26:544-549.

53 Leahy AL, Ellis RM, Quill DS, et al: High-fibre diet in symptomatic diverticular disease of the colon. Ann R Coll Surg Engl 1985;67:173-174.

54 Strate LL, Liu YL, Syngal S, et al: Nut, corn, and popcorn consumption and the incidence of diverticular disease. JAMA 2008;300:907-914.

55 Hjern F, Wolk A, Hakansson N: Smoking and the risk of diverticular disease in women. Br J Surg 2011;98: 997-1002.

56 Rosemar A, Angeras U, Rosengren A: Body mass index and diverticular disease: a 28 -year follow-up study in men. Dis Colon Rectum 2008;51:450-455. 
57 Aldoori WH, Giovannucci EL, Rimm EB, et al: A prospective study of alcohol, smoking, caffeine, and the risk of symptomatic diverticular disease in men. Ann Epidemiol 1995;5:221-228.

58 Humes DJ, Solaymani-Dodaran M, Fleming KM, et al: A population-based study of perforated diverticular disease incidence and associated mortality. Gastroenterology 2009;136:1198-1205.

59 Turunen P, Wikstrom H, Carpelan-Holmstrom, et al: Smoking increases the incidence of complicated diverticular disease of the sigmoid colon. Scand J Surg 2010; 99:14-17.

60 Papagrigoriadis S, Macey L, Bourantas N, et al: Smoking may be associated with complications in diverticular disease. Br J Surg 1999;86:923-926.

61 Usai P, Ibba I, Lai M, et al: Cigarette smoking and appendectomy: effect on clinical course of diverticulosis. Dig Liver Dis 2011;43:98-101.

62 Tsuruoka N, Iwakiri R, Hara M, et al: NSAIDs are a significant risk factor for colonic diverticular hemorrhage in elder patients: evaluation by a case-control study. J Gastroenterol Hepatol 2011;26:1047-1052.

63 Jansen A, Harenberg S, Grenda U, et al: Risk factors for colonic diverticular bleeding: a westernized community based hospital study. World J Gastroenterol 2009; 15:457-461.

64 Yamada A, Sugimoto T, Kondo S, et al: Assessment of risk factors for colonic diverticular hemorrhage. Dis Colon Rectum 2008;51:116-120.

65 Tonnesen H, Engholm G, Moller H: Association between alcoholism and diverticulitis. Br J Surg 1999;86: 1067-1068.

66 Strate LL, Liu YL, Aldoori WH, et al: Obesity increases the risks of diverticulitis and diverticular bleeding. Gastroenterology 2009;136:155-122.e111.

67 Kopylov U, Ben-Horin S, Lahat A, et al: Obesity, metabolic syndrome and the risk of development of colonic diverticulosis. Digestion 2012;86:201-205.

68 Konvolinka CW: Acute diverticulitis under age forty. Am J Surg 1994;167:562-565.

69 Schechter S, Mulvey J, Eisenstat TE: Management of uncomplicated acute diverticulitis: results of a survey. Dis Colon Rectum 1999;42:470-475; discussion 475476.

70 Zaidi E, Daly B: CT and clinical features of acute diverticulitis in an urban US population: rising frequency in young, obese adults. AJR Am J Roentgenol 2006;187: 689-694.

71 Strate LL, Liu YL, Aldoori WH, et al: Physical activity decreases diverticular complications. Am J Gastroenterol 2009; 104:1221-1230.

72 Hjern F, Wolk A, Hakansson N: Obesity, physical inactivity, and colonic diverticular disease requiring hospitalization in women: a prospective cohort study. Am J Gastroenterol 2012;107:296-302.

73 Aldoori WH, Giovannucci EL, Rimm EB, et al: Prospective study of physical activity and the risk of symptomatic diverticular disease in men. Gut 1995;36:276282.

74 Williams PT: Incident diverticular disease is inversely related to vigorous physical activity. Med Sci Sports Exerc 2009;41:1042-1047.

75 Nguyen GC, Sam J, Anand N: Epidemiological trends and geographic variation in hospital admissions for diverticulitis in the United States. World J Gastroenterol 2011;28:1600-1605.

76 Ricciardi R, Roberts PL, Read TE, et al: Cyclical increase in diverticulitis during the summer months. Arch Surg 2011;146:319-323.

77 Maguire LH, Song M, Strate LE, et al: Higher serum levels of vitamin $\mathrm{D}$ are associated with reduced risk of diverticulitis. Clin Gastroenterol Hepatol 2013;16311635.

Risk Factors for Diverticulosis, Diverticulitis

Diverticular Perforation, and Bleeding
78 Maguire LH, Song M, Strate LL, et al: Association of geographic and seasonal variation with diverticulitis admissions. JAMA Surg 2015;150:74-77.

79 Sakuta H, Suzuki T: Prevalence rates of type 2 diabetes and hypertension are elevated among middle-aged Japanese men with colonic diverticulum. Environ Health Prev Med 2007;12:97-100.

80 Scheff RT, Zuckerman G, Harter H, et al: Diverticular disease in patients with chronic renal failure due to polycystic kidney disease. Ann Intern Med 1980;92: 202-204.

81 McCune TR, Nylander WA, van Buren DA, et al: Colonic screening prior to renal transplantation and its impact on post-transplant colonic complications. Clin Transplant 1992;6:91-96.

82 Dominguez Fernandez E, Albrecht KH, Heemann U, et al: Prevalence of diverticulosis and incidence of bowel perforation after kidney transplantation in patients with polycystic kidney disease. Transpl Int 1998; 11:28-31.

83 Sharp CK, Zeligmann BE, Johnson AM, et al: Evaluation of colonic diverticular disease in autosomal dominant polycystic kidney disease without end-stage renal disease. Am J Kidney Dis 1999;34:863-868.

84 Lederman ED, McCoy G, Conti DJ, et al: Diverticulitis and polycystic kidney disease. Am Surg 2000;66:200203.

85 Pourfarziani V, Mousavi-Nayeeni SM, Ghaheri H, et al: The outcome of diverticulosis in kidney recipients with polycystic kidney disease. Transplant Proc 2007; 39:1054-1056.

86 Morris CR, Harvey IM, Stebbings WS, et al: Incidence of perforated diverticulitis and risk factors for death in a UK population. Br J Surg 2008;95:876-881.

87 Parnaby CN, Barrow EJ, Edirimanne SB, et al: Colorectal complications of end-stage renal failure and renal transplantation: a review. Colorectal Dis 2012;14:403415.

88 Tyau ES, Prystowsky JB, Joehl RJ, et al: Acute diverticulitis: a complicated problem in the immunocompromised patient. Arch Surg 1991;126:855-859.

89 Soravia C, Baldi A, Kartheuser A, et al: Acute colonic complications after kidney transplantation. Acta Chir Belg 1995;95:157-161.

90 Detry O, Honore P, Meurisse M, et al: Diverticulosis in the immunocompromised patients. Acta Chir Belg 1999;99:100-102.

91 Mueller XM, Tevaearai HAT, Stumpe F, et al: Gastrointestinal disease following heart transplantation. World J Surg 1999;23:650-656.

92 Hwang SS, Cannom RR, Abbas MA, et al: Diverticulitis in transplant patients and patients on chronic steroid therapy: a systematic review. Dis Colon Rectum 2010; 53:1699-1707.

93 Qasabian RA, Meager AP, Lee R, et al: Severe divertic ulitis after heart, lung, and heart-lung transplantation. J Heart Lung Transplant 2004;23:845-849.

94 Salem L, Anaya DA, Roberts KE, et al: Hartmann's colectomy and reversal in diverticulitis: a populationlevel assessment. Dis Colon Rectum 2005;48:988-995.

95 Sachar DB: Diverticulitis in immunosuppressed patients. J Clin Gastroenterol 2008;42:1154-1155.

96 Von Rahden BHA, Jurowich C, Kircher S, et al: Allergic predisposition, histamine and histamine receptor expression (H1R, H2R) are associated with complicated courses of sigmoid diverticulitis. J Gastrointest Surg 2012;16:173-182.

97 Niikura R, Nagata N, Akiyama J, et al: Hypertension and concomitant arteriosclerotic diseases are risk factors for colonic diverticular bleeding: a case-control study. Int J Colorectal Dis 2012;27:1137-1143.

98 Chen CY, Wu CC, Jao SW, et al: Colonic diverticular bleeding with comorbid diseases may need elective colectomy. J Gastrointest Surg 2009;13:516-520.
99 Chapman J, Davies M, Wolff B, et al: Complicated diverticulitis. Is it time to rethink the rules? Ann Surg 2005;242:576-583.

100 Sheer AJ, Heckman JE, Schneider EB, et al: Congestive heart failure and chronic obstructive pulmonary disease predict poor surgical outcomes in older adults undergoing elective diverticulitis surgery. Dis Colon Rectum 2011;54:1430-1437.

101 Yoo PS, Garg R, Salomone LF, et al: Medical comorbidities predict the need for colostomy for complicated and recurrent diverticulitis. Am J Surg 2008;196:710-714.

102 Klarenbeek BR, Samuels M, van der Wal MA, et al: Indications for elective sigmoid resection in diverticular disease. Ann Surg 2010;251:670-674.

103 Mueller MH, Karpitschka M, Renz B, et al: Co-morbidity and postsurgical outcome in patients with perforated sigmoid diverticulitis. Int J Colorectal Dis 2011; 26:227-234.

104 Burkitt DP: Some diseases characteristic of modern Western civilization. Br J Med 1973;1:274-278.

105 Ekbom A: Is diverticular disease associated with colonic malignancy? Dig Dis 2012;30:46-50.

106 Boulos PB, Karamanolis DG: Is colonoscopy necessary in diverticular disease? Lancet 1984;1:95-96.

107 Morini S, De Angelis P, Manurita L, et al: Association of colonic diverticula with adenomas and carcinomas. A colonoscopic experience. Dis Colon Rectum 1988; 31:793-796.

108 Stefansson T, Ekbom A, Sparen P, et al: Increased risk of left sided colon cancer in patients with diverticular disease. Gut 1993;34:499-502.

109 Meurs-Szojda MM, Terhaar sive Droste JS, Kuik DJ, et al: Diverticulosis and diverticulitis form no risk for polyps and colorectal neoplasia in 4,241 colonoscopies. Int J Colorectal Dis 2008;23:979-984.

110 Lam TJ, Meurs-Szojda MM, Gundlach L, et al: There is no increased risk for colorectal cancer and adenomas in patients with diverticulitis: a retrospective longitudinal study. Colorectal Dis 2010;12:1122-1126.

111 Granlund J, Svensson T, Granath F, et al: Diverticular disease and the risk of colon cancer - a populationbased case-control study. Aliment Pharmacol Ther 2011;34:675-681.

112 Morini S, Zullo A, Hassan C, et al: Diverticulosis and colorectal cancer. Between lights and shadows. J Clin Gastroenterol 2008;42:763-770.

113 Corder A: Steroids, non-steroidal anti-inflammatory drugs, and serious septic complications of diverticular disease. Br Med J 1987;295:1238.

114 Wilson RG, Smith AN, Macintyre IMC: Complications of diverticular disease and non-steroidal anti-inflammatory drugs: a prospective study. Br J Surg 1990;77: 1103-1104.

115 Campbell K, Steele RJ: Non-steroidal anti-inflammatory drugs and complicated diverticular disease: a casecontrol study. Br J Surg 1991;78:190-191.

116 Langman MJS, Morgan L, Worrall A: Use of anti-inflammatory drugs by patients admitted with small or large bowel perforations and haemorrhage. Br Med J (Clin Res Ed) 1985;290:347-349.

117 Wilson RG, Smith AN, Macintyre IMC: Non-steroidal anti-inflammatory drugs and complicated diverticular disease: a case-control study. Br J Surg 1991:78:1148.

118 Goh H, Bourne R: Non-steroidal anti-inflammatory
. drugs and perforated diverticular disease: a case-control study. Ann R Coll Surg Engl 2002;84;93-96.

119 Mpofu, S, Mpofu CM, Hutchinson D, et al: Steroids, non-steroidal anti-inflammatory drugs, and sigmoid diverticular abscess perforation in rheumatic conditions. Ann Rheum Dis 2004;63:588-590.

120 Piekarek K, Israelsson LA: Perforated colonic diverticular disease: the importance of NSAIDS, opioids, corticosteroids, and calcium channel blockers. Int J Colorectal Dis 2008;23:1193-1997. 
121 Morris CR, Harvey IM, Stebbings WS, et al: Antiinflammatory drugs, analgesics and the risk of perforated colonic diverticular disease. Br J Surg 2003;90: 1267-1272.

122 Aldoori WH, Giovanucci EL, Rimm EB, et al: Use of acetaminophen and nonsteroidal anti-inflammatory drugs: a prospective study and the risk of symptomatic diverticular disease in men. Arch Fam Med 1998;7: 755-260.

123 Strate LL, Liu YL, Huang ES, et al: Use of aspirin or nonsteroidal antiinflammatory drugs increase risk for diverticulitis and diverticular bleeding. Gastroenterology 2011;140:1427-1433.
124 Humes DJ, Fleming KM, Spiller RC, et al: Concurrent drug use and the risk of perforated colonic diverticular disease: a population-based case-control study. Gut 2011;60:219-224

125 Canter JW, Shorb PE: Acute perforations of colonic diverticula associated with prolonged adrenocorticosteroid therapy. Am J Surg 1971;121:46-51.

126 Weiner HL, Rezai AR, Cooper PR: Sigmoid diverticular perforation in neurosurgical patients receiving highdose corticosteroids. Neurosurgery 1993;33:40-43.
127 Morris CR, Harvey IM, Stebbings WS, et al: Do calcium channel blockers and antimuscarinics protect against perforated colonic diverticular disease? A case control study. Gut 2003;52:1734-1777.

128 Lanas A, Garcia-Rodriguez LA, Polo-Tomas M, et al: The changing face due to gastrointestinal bleeding and perforation. Aliment Pharmacol Ther 2011;33:585-591. 